\title{
Phototoxic and Photoallergic Reactions
}

\author{
Margarida Gonçalo
}

\section{Contents}

\subsection{Introduction.}

18.2 General Mechanisms of Photosensitivity .....

18.2.1 Phototoxicity vs. Photoallergy .............

18.3 Clinical Patterns of Photosensitivity ....... 3

18.3.1 Acute Manifestations of Photosensitivity ...... 5

18.3.2 Subacute Manifestations of Photosensitivity.... 5

18.3.3 Delayed and Late Effects of Photosensitivity .... 8

18.4 Main Topical and Systemic Photosensitizers . . 8

18.4.1 UV Filters. ........................ 9

18.4.2 Plants Causing Phytophotodermatitis ........ 10

18.4.3 Photosensitive Drugs . . . . . . . . . . . . . . . . . 11

18.5 Conclusions $\ldots \ldots \ldots \ldots \ldots \ldots \ldots \ldots \ldots \ldots \ldots$

References............................ 14

\section{Gonçalo}

Clinic of Dermatology, Coimbra University Hospital,

University of Coimbra, Praceta Mota Pinto,

3000-175 Coimbra, Portugal

e-mail: mmgoncalo@netcabo.pt

\subsection{Introduction}

[AU1]

1 Phototoxicity and photoallergy are different expressions 5 of an abnormal skin reaction from the exposure to light, 6 usually enhanced by endogenous or exogenous sub- 7 stances that are selectively activated by solar radiation. 8

This can occur with artificial light sources (sun 9 lumps used for aesthetic or therapeutic purposes or 10 ultraviolet (UV) sources in occupational settings), but 11 mostly occur on sun exposure. From the solar spec- 12 trum that reaches the earth, UV radiation, and particu- 13 larly UVA $(320-400 \mathrm{~nm})$, is responsible for most cases 14 of photosensitivity. Even though some chromophores 15 absorb in the UVB (290-320 nm) and UVB is more 16 energetic, UVA penetrates the skin more deeply and, 17 particularly for systemic chromophores, this is cer- 18 tainly the most important spectrum for inducing photo- 19 dermatosis [1]. Only exceptional reports have a well- 20 documented exogenous photosensitivity exclusively 21 from UVB [2].

Photosensitivity from topical agents, once frequent 23 and often associated with persistent reactions to light, is 24 now becoming rare $[3,4]$, as the main topical photosen- 25 sitizers are removed from the market, or maybe photo- 26 sensitivity is underreported or underdiagnosed [5]. On 27 the other hand, and even though sun avoidance is rec- 28 ommended in those exposed to known photosensitizers, 29 new drugs are reported to have photosensitizing proper- 30 ties, eventually associated with late problems. 31

Therefore, photosensitivity is still a problem and a 32 field on intense research. New photosensitizers are 33 reported as a cause of skin disease, whereas others are 34 used for phtnototherapy. Studies are still being under- 35 taken on the mechanisms and chromophores, respon- 36 sible for diseases associated with photosensitivity, 37 such as HIV infection [6, 7]. 


\subsection{General Mechanisms of Photosensitivity} Vitamin D synthesis.
Normal skin has several molecules that are activated upon sun exposure and undergo chemical reactions the chromophores - which are important for our survival under the sun and necessary for our life. An example is 7-dehydrocholesterol which, upon activation by UVB, forms provitamin D3 necessary for

Photosensitivity develops when an abnormal chromophore, or a normal chromophore in exaggerated amounts, is present in the skin. When excited by a photon, these molecules suffer changes within the molecule itself, often also within neighboring molecules, in a cascade of events that result in skin damage and inflammation. This can occur through the direct molecular modification (isomerization, breaking of double bounds, oxidation) or production of free radicals, dependent or not on oxygen, which modify unsaturated lipids of cell membranes, aromatic amino acids of proteins, or DNA or RNA bases of nucleic acids. If the repair mechanisms do not act immediately, there is damage and/or death of skin cells and inflammatory mediators are produced (prostaglandins, IL-1, 6, 8, other cytokines, and chemokines) with consequent skin lesions - this is briefly the mechanism of phototoxicity [1]. In some circumstances, the energy of the photon can be used by the chromophore to transform itself into a new molecule (photoproduct) or to bind an endogenous peptide and, therefore, form a hapten or an allergen that can be recognized by the skin immune system. In these cases, photoallergy may develop with a sensitization phase and effector phase similar to allergic contact dermatitis (see Chap. 8 for more details).

Apart from the capacity to generate free radicals responsible for phototoxicity, several phototoxic substances, such as psoralens, chlorpromazine, and fluorquinolones, have shown to induce chromosomal damage in the presence of UVR. Therefore, both in vitro and in animal studies, they were photomutagenic and photoimmunosuppressive, with consequent implications in photocarcinogenesis [8-12]. Epidemiological studies and recent reports are showing this may also be significant for humans. In 1999, the group of Przybilla showed an association between actinic keratosis and the use of potentially photosensitizing chemicals [13]. More recent data tend to confirm an increased risk in patients on long-term PUVA treatments [14] and, also in those exposed to fluorquinolones, diuretics [15], and voricon- 86 azole [16]. The chromophore responsible for the photo- 87 sensitive reaction can be an endogenous molecule, like 88 a porphyrin that accumulates in the skin due to an inborn 89 metabolic error, or it can be an exogenous molecule that 90 is applied on the skin or reaches the skin through the 91 systemic circulation. In many diseases, the chromophore 92 has been identified, but there are many idiopathic photo- 93 dermatoses for which the main chromophore is still 94 unknown. Some resemble exogenous photoallergic 95 reactions, like "Lucite Estivale Bénigne," polymorphic 96 light eruption, or chronic actinic dermatitis, whereas 97 others have very typical clinical patterns, like hydroa 98 vacciniforme or actinic prurigo. Also, as sunscreens are widely used to prevent skin lesions in these photodermatoses, these patients frequently develop allergic or photoallergic contact dermatitis to UV filters [3, 4], thereby associating the effect of endogenous and exogenous chromophores.

In some patients, photosensitivity develops because of a deficiency in the capacity to repair UV aggression, due to a genetic problem (xeroderma pigmentosum, Bloom's syndrome) or a transient imbalance of antioxidant skin defense (in pellagra due to reduced levels of niacin in diet or alcohol consumption), or because the natural mechanisms of skin protection are deficient (vitiligo, albinism) [1, 17].

\section{Core Message}

> UV activation of an endogenous or an exogenous skin chromophore can induce an inflammatory reaction (phototoxicity) or a $\mathrm{T}$-cell-mediated reaction (photoallergy).

\subsubsection{Phototoxicity vs. Photoallergy}

In theory, it is easy to differentiate photoallergy, a 114 T-cell-mediated hypersensitivity reaction to an allergen formed upon UV exposure, from phototoxicity, that represents an exaggerated inflammatory response to the sun enhanced by an exogenous chromophore. Classically, photoallergy develops only in a limited number in individuals, needs previous sensitization but is extensive to cross-reactive chemicals, is subject to 


\section{Author's Proof}

18 Phototoxic and Photoallergic Reactions

flare-ups, is not dependent on the dose of the exogenous chromophore and needs low UV exposure, appears as eczema that can spread to nonexposed sites, and on skin biopsy, there is mainly spongiosis as in eczema. Phototoxicity is more frequent and considered to develop in every individual, as long as enough photosensitizer and sun exposure are present; occurs even on a first and single contact, with no flare-ups or crossreactions; and appears mainly as well-demarcated erythema exclusively on sun-exposed areas (mimicking sunburn); and on histology, apoptotic keratinocytes (sunburn cells) are abundant (Table 18.1).

But, even though there are typical aspects of these two polar types of photosensitivity, some molecules may induce both phototoxic and photoallergic dermatitis. Although rare, this can occur with plant furocoumarins (Ruta graveolans, Ficus carica, Umbeliferae) or during photochemotherapy, as individuals become reactive to very low concentrations of psoralens [18]. Also, for mainly phototoxic drugs like promethazine and lomefloxacin, a few patients develop photoallergy, reacting to very low doses of the drug or sun exposure [19-21]. Most probably, as occurs with contact allergens that have an inherent "irritant" potential to awaken the innate immune system necessary to promote the sensitization process [22], photoallergens are photoactive molecules with some inherent phototoxicity, which may be the "danger signal" necessary to initiate the sensitizing process.
Also, although it is considered that photoallergy does not occur on a first contact due to the need for previous sensitization, this may not be necessary if you have already been sensitized by contact to a similar molecule. This occurs in patients who are allergic to thiomersal, namely to its moiety thiosalicylic acid, who develop photosensitivity to piroxicam on the first intake of the drug. Upon UVA irradiation, piroxicam is photodecomposed into a molecule very similar antigenically and structurally to thiosalicylic acid, responsible for piroxicam photoallergy [23-25].

Also, although phototoxicity is considered to occur in every patient as long as enough chromophore and sun are present at the same time, there is also individual susceptibility to phototoxicity from drugs and phytophotodermatitis, even though the parameters that characterize this susceptibility are not precisely known.

Therefore, and although, in theory, we can separate these two mechanisms - phototoxicity and photoallergy, there is often an overlap between both.

\subsection{Clinical Patterns of Photosensitivity}

The clinical patterns of photosensitive disorders are 173 sometimes very typical, like phytophotodermatitis, acute 174 exaggerated sunburn from exposure to a phototoxic

Table 18.1 Distinction between phototoxicity and photoallergy

\begin{tabular}{lll}
\hline & Phototoxicity & Photoallergy \\
\hline Frequency & High & Low \\
\hline Latency period/sensitization & No & Yes \\
\hline Doses of UV/photosensitizer & High & Low \\
\hline Cross-reactions & No & Yes \\
\hline Morphology of lesions & Sunburn, polymorphic & Eczema, erythema multiforme \\
\hline Sharp limits & Yes & No \\
\hline Covered areas & Not involved & Possibly involved \\
\hline Resolution & Quick & May recur, persistent reactors \\
\hline Residual hyperpigmentation & Yes & No \\
\hline Histology & Sunburn cells & Eczema \\
\hline Pathomechanism & DNA/cell damage & Type IV hypersensitivity \\
\hline
\end{tabular}

$R O S$ reactive oxygen species 


\section{Author's Proof}

18

176
177

178

179

180

[t $\Delta \cup 2]$ Table 18.2 Clinical patterns of photosensitivity

\begin{tabular}{|c|c|c|}
\hline $\mathrm{t} 2.2$ & $\begin{array}{l}\text { Predominant in } \\
\text { phototoxicity }\end{array}$ & $\begin{array}{l}\text { Predominant in } \\
\text { photoallergy }\end{array}$ \\
\hline $\mathrm{t} 2.4$ & Exaggerated "sunburn" & Urticaria of sun exposed area \\
\hline t2.5 & Pseudoporphyria & Acute or subacute eczema \\
\hline t2.6 & Photoonycholysis & Cheilitis \\
\hline $\mathrm{t} 2.7$ & Hyperpigmentation & Erythema multiform-like \\
\hline $\begin{array}{l}\mathrm{t} 2.8 \\
\mathrm{t} 2.9\end{array}$ & $\begin{array}{l}\text { Hypopigmentation } \\
\text { (vitiligo-like lesions) }\end{array}$ & Lichenoid reactions \\
\hline $\begin{array}{l}\mathrm{t} 2.10 \\
\mathrm{t} 2.11\end{array}$ & $\begin{array}{l}\text { Telangiectasia } \\
\text { Purpura }\end{array}$ & $\begin{array}{l}\text { Subacute or chronic lupus } \\
\text { erythematosus }\end{array}$ \\
\hline $\begin{array}{l}\mathrm{t} 2.12 \\
\mathrm{t} 2.13\end{array}$ & $\begin{array}{l}\text { Actinic keratosis and } \\
\text { squamous cell carcinoma }\end{array}$ & Pellagra like-reactions \\
\hline
\end{tabular}

drug, and, among some idiopathic photodermatoses, hydroa vacciniforme and xeroderma pigmentosum. But, sometimes, the diagnosis or even the suspicion of photosensitivity is not so obvious. It is the example of acute or chronic eczematous skin lesions, extending to covered areas, with a less well-established relation with sun exposure (often a regular exposure), like in chronic actinic dermatitis or in photoaggravation of rosacea or lupus erythematosus by sunscreens.

The clinical manifestations of photosensitivity are very polymorphic (Table 18.2), extending from urticaria through eczema or subacute lupus erythematosus up to vitiligo-like lesion or squamous cell carcinomas [14, 16, 19].

In some cases, exposure to sun induces immediate reactions, like in solar urticaria, but the appearance of skin lesions may be delayed 1 or 2 days, as in photoallergic contact dermatitis or systemic photoallergy, several days or weeks, as in pseudoporphyria or subacute lupus erythematosus, or even years, as in photocarcinogenesis enhanced by a long exposure to the sun and photoactive drugs.

Localization of the lesions in photosensitivity from a topical agent draws the area of application and concomitant sun exposure. But localization and distribution of lesions may be more peculiar extending to areas of accidental contact, as in a contra-lateral limb (kissing faces of the legs) or areas of inadvertent spread by the hands or other contaminated objects [26]. Also, as some topical drugs are absorbed through the skin (NSAIDs), the distribution of the lesions can be similar to systemic photosensitivity. This is usually very

squamous cell carcinoma typical, as the reaction frequently involves, in a sym- 208 metric distribution, all exposed areas of the face, the 209 $\mathrm{V}$-shaped area of the neck, and upper chest, dorsum of 210 the hands and forearms, while shaded areas are spared. 211 This corresponds, in the face, to the upper eyelids, 212 upper lip, deep wrinkles (Fig. 18.1), retroauricular 213 areas, submandibular area (Fig. 18.2), and areas cov- 214 ered by the beard or hair; and in the body, to the large 215 body folds, like the axillae, groins, finger webs, and to 216 all the areas covered by clothing or other accessories 217 (watch strip, shoes). This allows a distinction from air- 218 borne dermatitis where the allergen in the environment 219 can localize in these shaded areas and induce skin 220 lesions, without the need for sun exposure. 221

In exceptional cases where sun exposure is asymmetric, this pattern can be different, as in car drivers who only expose the left arm. Sometimes, in systemic photosensitivity, the lower lip is mainly or almost exclusively involved, because of its higher exposure and, most probably, because of the lower thickness of the corneal layer, which is one of the main defenses against solar radiation [27-29].

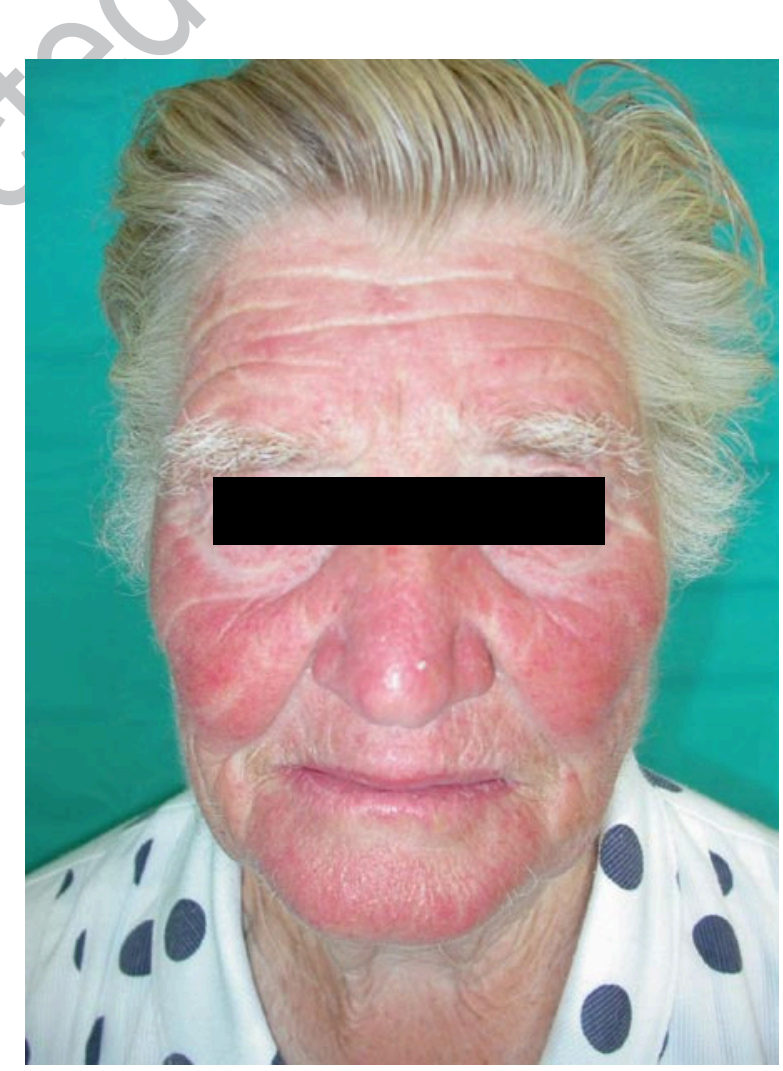

Fig. 18.1 Acute phototoxicity from amiodarone, mimicking sunburn and sparing the deep wrinkles 


\section{Author's Proof}

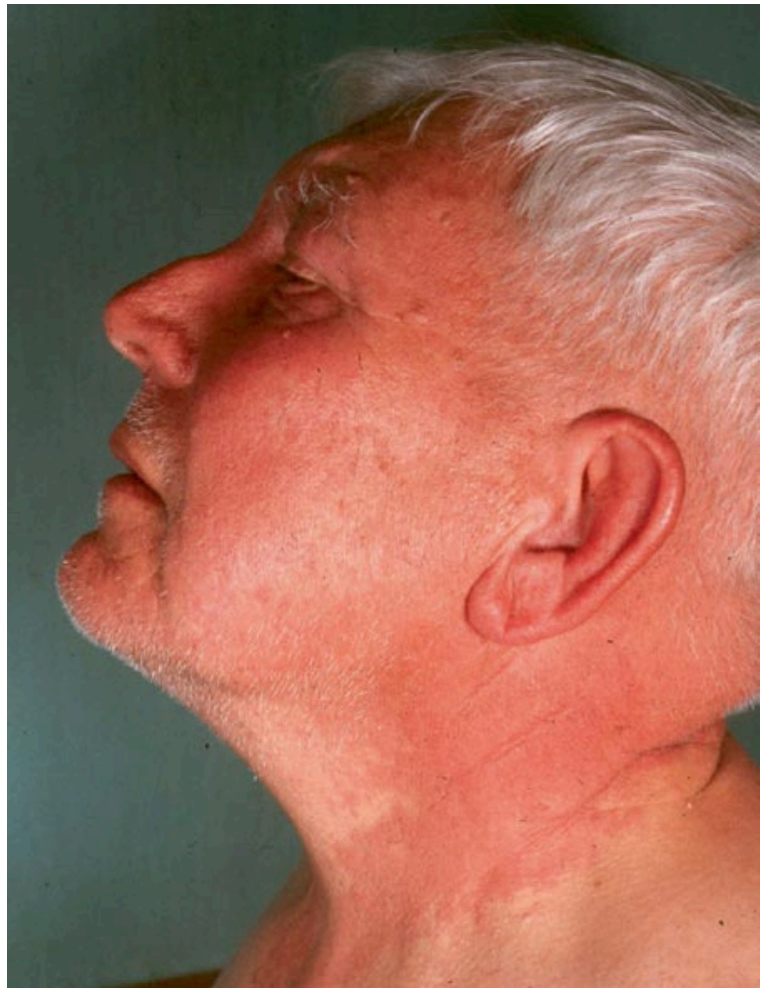

Fig. 18.2 Acute eczema from systemic piroxicam, sparing the submandibular shaded area

\section{Core Message}

> Phototoxic reactions present mainly as an exaggerated sunburn, but may be very polymorphic and difficult to distinguish from photoallergy.

Apart from idiopathic solar urticaria, for which a chromophore is not identified, urticaria as a manifestation of photosensitivity from an exogenous substance has been rarely described with 5 -aminolevulinic acid, used in photodynamic therapy [30], with oxybenzone [31, 32] and chlorpromazine [33]. Nevertheless for some drugs, like amiodarone and benoxaprofen (already removed from the market), immediate prickling and burning with transient erythema may occur as a mani- 24 festation of photosensitivity [14].

\subsubsection{Acute Phototoxicity, Mimicking} Sunburn

The main acute clinical manifestation of phototoxic- 245 ity is a well-demarcated acute erythema or edema 246 with prickling and burning, eventually progressing to 247 bullae with skin pain, which develops within 12-24 h 248 of sun exposure. This gives rise to large sheets of epi- 249 dermal detachment within the next days and can 250 resolve with residual hyperpigmentation. This is simi- 25 lar to exaggerated sunburn (Fig. 18.1), and eventually, 252 can also be associated with systemic symptoms like 253 fever.

\subsubsection{Acute Photoallergic Eczema}

Photoallergy occurs usually as a pruritic eczematous reaction of the sun exposed areas, with irregular limits, often extending to covered areas. It develops more than 24-48 $\mathrm{h}$ after sun exposure, and not on a first contact. This resolves, like in acute eczema, with desquamation and no hyperpigmentation. Distribution of lesions is usually symmetric in systemic photosensitivity and shaded areas are also protected but not as sharply as in phototoxicity (Fig. 18.2).

In the more intense photoallergic reactions, typical or atypical target lesions, characteristic of erythema multiforme and with histopathology of erythema multiforme, can be seen in association with the eczematous plaques, mainly at its limits or at distant sites, as was described for ketoprofen [34, 35]

In some cases, a systemic photosensitizer can induce a photodistributed erythema multiforme or toxic epidermal necrolysis, as described with paclitaxel [36], naproxen [37] and clobazam [38].

\section{年}

(n)

\section{.} (a)

Other less frequent clinical patterns develop with a 277 delay of days/weeks after exposure to the photosensi- 278 tizer and the sun, or rarely acutely. These patterns that 279 


\section{Author's Proof}

evoke mainly a phototoxic reaction are pseudoporphyria, photoonycholysis, hyper or hypopigmentation, telangiectasia, and purpura.

\subsubsection{Pseudoporphyria}

Pseudoporphyria with chronic skin fragility and flaccid bullae on noninflamed sun-exposed skin, occasionally with later milia formation, mimicking porphyria cutanea tarda on clinical and histopathology (bullae formation below the lamina densa), was described initially for nalidixic acid, furosemide, and naproxen, predominantly in children [14, 39] and, more recently, for ciprofloxacin [40], celecoxib [41, 42], voriconazole [28, 43], and imatinib [44]. This may represent a typical phototoxic reaction where the drug, as the chromophore, has a similar mechanism of inducing the phototoxic reaction (singlet oxygen) as the uroporphyrin in the hereditary disease [14, 39].

\subsubsection{Photoonycholysis}

Photoonycholysis, with a half moon distal onycholysis of one or several nails, is a typical pattern of phototoxicity and often the single manifestation of this reaction. It appears late (2-3 weeks after drug intake and sun exposure), may be preceded by pain in the nail apparatus, and occurs mainly with tetracyclines (demethylchlortetracyclie or doxycycline) [45], psoralens, and fluorquinolones [46]. There is no definite explanation for the single involvement of the nail: the nail bed is relatively unprotected from sunlight, contains less melanin, the nail plate may work as a lens, and the inflammatory reaction induces detachment of the nail plate from the nail bed [45-47].

\subsubsection{Dyschromia}

Hyperpigmentation that follows mainly an acute phototoxic reaction is frequently due to the residual melanocytic hyperpigmentation, and is very typical in phytophotodermatitis, or after lichenoid reactions, e.g., from phenothiazines (Fig. 18.3).

In rare occasions, like those induced by flutamide, vitiliginous lesions with sharp limits occur after the acute photosensitive reaction [48, 49].

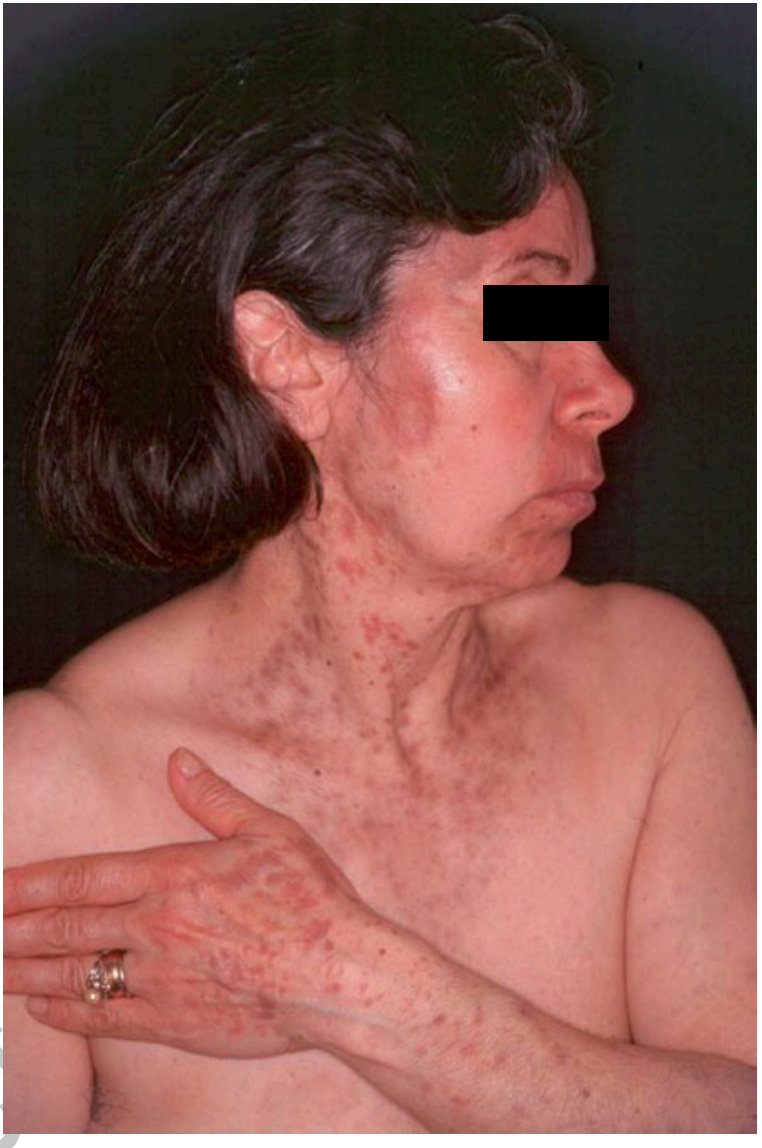

Fig. 18.3 Lichenoid lesions and pigmentation in the photoexposed areas in a patient taking thioridazine for several months

Hyperpigmentation, or more precisely dyschromia, 320 may occur from the accumulation of the drug or drug 321 metabolites in the dermis, namely from amiodarone, 322 minocycline, and phenothiazines [50, 51]. Apart from 323 acute photosensitivity reaction that occurs more fre- 324 quently, a smaller percentage of these patients, mainly 325 those with lower phototypes, develop a golden-brown, 326 slate gray, or bluish color on sun-exposed areas. This 327 discoloration develops later and persists much longer 328 than residual melanocytic hyperpigmentation [14, 50] 329 (Fig. 18.4).

\subsubsection{Other Clinical Patterns}

Telangiectasia as a manifestation of photosensitivity has 332 been reported with calcium channel blockers [52] and 333 the telangiectatic pattern of photoaging with lesions 334 mainly in the lateral folds of the neck, sparing the shaded 335 


\section{Author's Proof}

18 Phototoxic and Photoallergic Reactions

Fig. 18.4 Chronic phototoxicity in a patient on a long-term treatment with minocycline. Note the lichenification, with ectropion and the brownish pigmentation (a) and onycholysis in all his fingers (b). Photoonycholysis can occur as an isolated manifestation of photosensitivity
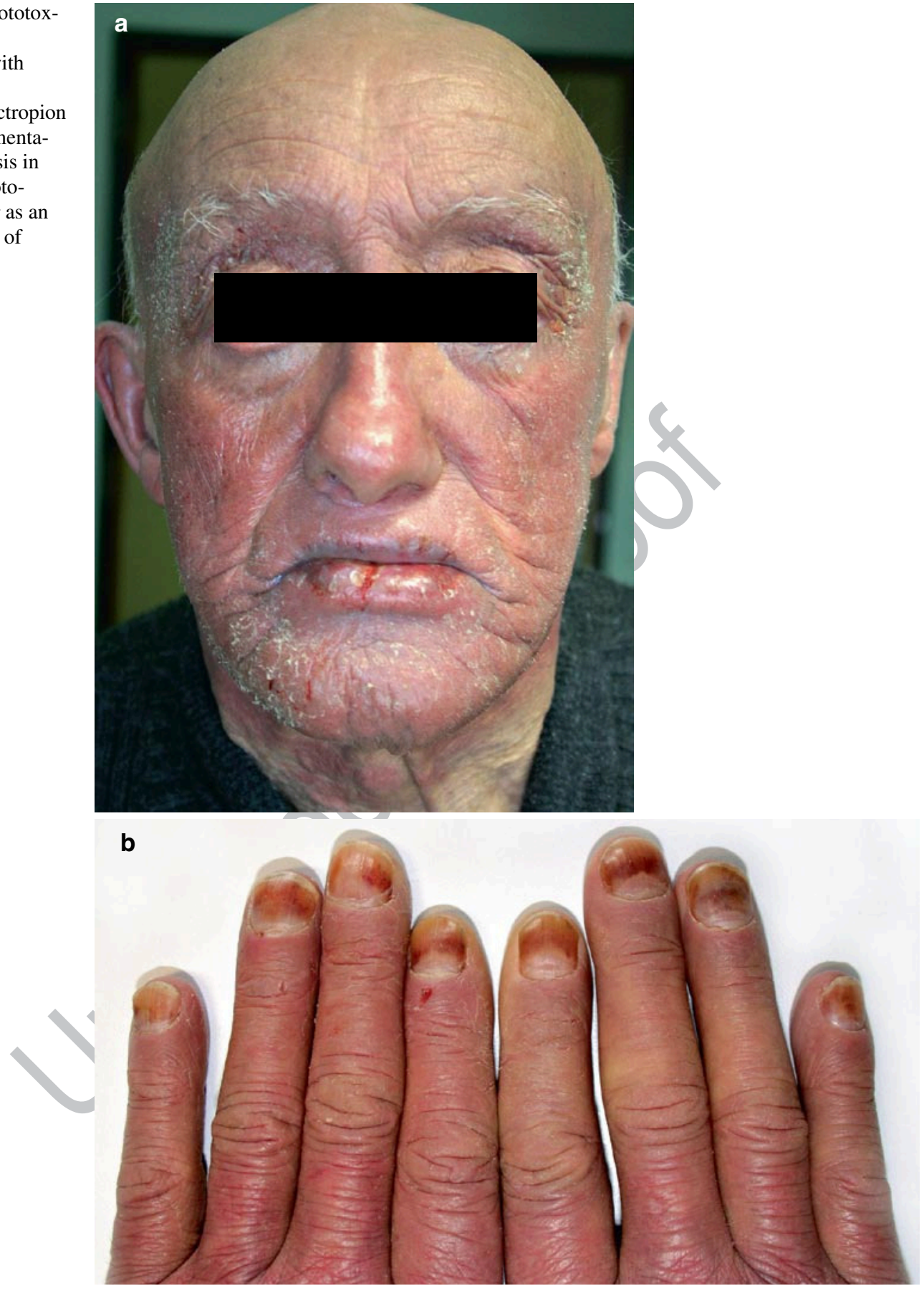

skin under the chin, is frequently observed in patients chronically exposed to photoactive drugs. In rare cases, petechial purpura with sharp limits on shaded areas was described with ciprofloxacin [53].
Pellagra is associated with the prolonged use of iso- $\quad 380$ niazid, which consumes niacin for its metabolization, and pellagroid reactions were reported with anticancer 338 agents such as 6-mercaptopurin and 5-fluoruracil. 
18

\subsubsection{Delayed and Late Effects of Photosensitivity}

\subsubsection{Lupus Erythematosus}

Cases of lupus erythematosus, both subacute and chronic, have been attributed to the exposure to exogenous drugs/ allergens and the sun. Most patients have anti-Ro autoantibodies, the hallmark of photosensitivity in lupus erythematosus. Lesions develop weeks or months after exposure on the exposed areas of face, neck, upper chest, and arms, as erythematosus and scaling annular lesions typical of subacute lupus erythematosus or, more rarely, chronic lesions on the face or V of the neck [14]. This was described initially for thiazide diuretics, calcium channel blockers, ACE inhibitors [54], terbinafine [55], and recently from the anticancer taxanes, paclitaxel, and docetaxel [36, 56]. The drugs may enhance UV-induced expression of the Ro antigen on the surface of keratinocytes, interfere with apoptosis or cytokine production, thereby promoting photosensitivity and the development of skin lesions in susceptible individuals [54].

\subsubsection{Chronic Actinic Dermatitis}

Chronic actinic dermatitis, more common in older men, can present as a photosensitive eczema or, more frequently, like a long-lasting chronic eczema with a brown-gray hyperpigmentation, skin edema, lichenification that resemble its lymphomatoid variant, and actinic reticuloid (Fig. 18.4). Also, on histology, large activated lymphocytes in the dermis mimic lymphoma. Lesions are localized on the photoexposed areas (face, sides and back of the neck, upper chest, and dorsum of the hands and forearms) and are aggravated by sun exposure; even this may not be very apparent because of the small amounts of UV necessary to aggravate the lesions. The hallmark of this disease is the extreme photosensitivity, even on covered areas, to UVB (reduced MED) and, often, also UVA and visible light $[7,57]$.

In many cases, these patients have previously suffered from an idiopathic photodermatosis, a chronic photodermatitis or, more frequently, from an airborne allergic contact dermatitis from perfumes, sesquiterpene lactones from Compositae, or colophony from conifers, and in its evolution, they become extremely photosensitive even with no further exposure to an 387 exogenous chromophore or allergen. An autoantigen 388 (DNA or RNA modified by plant products or another 389 autoantigen) may have been formed during the acute reaction or, may be the regular UV-induced immunosuppression did not work correctly and individuals were sensitized to this new autoantigen and developed a reaction similar to allergic contact dermatitis $[17,57]$.

\subsubsection{Enhancement of Photocarcinogenesis}

Recent reports are documenting the relation between exposure from photoactive molecules and increasing incidence of actinic keratosis or squamous cell carcinoma, in a parallel of what was observed with long time therapeutic exposure to PUVA. Apart from psoralens, naproxen, chlorpromazine, and the fluorquinolones, particularly lomefloxacin, also have the capacity to induce DNA aggression upon UV exposure, in vitro, and to increase epidermal neoplasia in animals [8, 9]. This concern may have to be taken into account, namely as severe photosensitivity associated with skin cancer has been observed with voriconazole [16] and ciprofloxacin (personal experience) and epidemiological studies seem to correlate exposure to photoactive drugs and an increase in the risk of developing actinic keratoses, nonmelanoma skin cancer and, even, malignant melanoma $[13,15]$. Also, photoaging may be enhanced by the exposure to topical or systemic photosensitizers.

\section{Core Message}

> On a long term, skin exposure to photoactive substances may enhance photocarcinogenesis.

\subsection{Main Topical and Systemic Photosensitizers}

There is a large and increasing list of photoactive mol- 417 ecules to which we can be exposed to in our daily life 418 and which can induce photosensitivity. But there has 419 been increasing concern on the evaluation of the photo- 420 toxic potential, particularly of cosmetics and consumer 421 
products, and very important photosensitizers have been eliminated or highly reduced in our ambience. These "historical" photosensitizers are musk ambrette and natural bergamot oil, removed by the perfume industry; the sunscreen isopropyldibenzoylmethane, withdrawn in 1994; the antibiotic olaquindox, a swine feed additive banned in 1998 by the European Commission [58]; and the halogenated salicylanilides removed from disinfectants and hygiene products in most countries since 1976. Nevertheless, even though some products are not available in Europe, they can be "imported" from other countries and induce photosensitivity [58, 59].

In most reports, the main topical photosensitizers are the UV filters [3, 60, 61], which represent 56-80\% of the cases diagnosed by photopatch testing [3, 62-64]. Furocoumarins from plants are an important source of photosensitivity, mainly in more sunny countries, and drugs are, by far, the most frequent photosensitizers in Southern Europe [62, 64-66].

\subsubsection{UV Filters}

Due to the increased awareness of the sun damaging effects, sunscreens are used in large amounts and UV filters are also present in cosmetics, like moisturizing and facial creams, lipstick, nail varnish, shampoos, and other hair products. Apart from protecting the skin and hair from solar aggression, they are intended to prevent the degradation of the product by the sun and, therefore, increase its shelf half life. But, happily, concurrent with this high use, adverse skin reactions from UV filters are not reported so frequently [3]. In recent studies, positive photopatch tests or photoaggravated reactions to UV filters occurred in 5.7-12\% of a total of about 2,400 patients tested [4, 62, 64-67].

The newer UV filters - Mexoryl SX (terephtalydene dicamphor sulfonic acid), Tinosorb $\mathrm{M}$ (methylenebis-benzotriazolyl tetramethylbutylphenol or bisoctrizole), and Tinosorb S (bis-ethylhexyloxyphenol methoxyphenyl triazine) - are photostable molecules and, in mixtures of several sunscreens, are able to stabilize older photo labile UV filters, like butyl methoxydibenzoylmethane and cinnamates. Therefore, they seem to be more efficient in protecting the skin from the harmful effects of UVR [68] and eventually in reducing photoallergic dermatitis, even from the other UV filters. Apparently, a single case of photoallergy was reported from Mexoryl SX [60] with no cases of 467 photoallergy from Tinosorb M or S. There are only 468 very rare cases of allergic contact dermatitis from the 469 surfactant decylglucoside that is used to solubilize the 470 active molecule of Tinosorb M [69, 70].

The other UV filters have been responsible for allergic contact and/or photocontact dermatitis, or photoaggravated contact dermatitis [4]. In the 50s and 60s, PABA ( $p$-aminobenzoic acid) was responsible for many cases of allergic and photoallergic contact dermatitis (4\% of the population in an American study) [68] and, therefore, since then it was seldom used. Nevertheless, a very recent case of photoallergic contact dermatitis was published [59].

In the studies from the 70 s till the end of the $90 \mathrm{~s}$, most frequent photosensitizers are the UVA filters, oxybenzone (benzophenone 3), and isopropyldibenzoylmethane $[31,63,64,67,71]$. At present, the latter is not produced anymore, and the other dibenzoylmethane on the market, butyl methoxydibenzoylmethane, is not such a potent photosensitizer. Many reactions previously reported were probably due to a cross-reaction [71].

Oxybenzone, still the most used UV filter, is being replaced in many sunscreens. Those sunscreens having a concentration higher than $0.5 \%$ must print a warning on the label. Nevertheless, in this setting or as a common ingredient in cosmetics, oxybenzone is still the most frequently used UV filter responsible for positive photopatch tests $[4,60,64,67]$. Rarely, it can also induce contact photocontact urticaria or anaphylaxis [32]. Sulisobenzone (benzophenone 4) and mexenone (benzophenone 10) induce allergic or photoallergic contact dermatitis less frequently [64, 72, 73].

Another concern on oxybenzone, and the other benzophenones, is related to its percutaneous absorption and its environmental spread, which may be harmful due to its potential estrogen-like effects [74].

Cinnamates, namely isoamyl- $p$-methoxycinnamate and ethylhexyl-p-methoxycinnamate, and 4-methylbenzylidene camphor, phenylbenzimidazole sulfonic acid, drometrizole trisiloxane (Mexoryl XL) and octyl dimethyl PABA (Padimate $\mathrm{O}$ ) are also regularly responsible for cases of photoallergy [3, 4, 62, 64, 66, 67]. Other UVB filters, namely the salycilates (octylsalycilate and homosalate) and octocrylene are seldom reported to cause allergic or photoallergic contact dermatitis [75, 76], except in an Italian study where octocrylene was the most frequent UV filter responsible for photopatch test reactions [66]. 


\section{Author's Proof}

M. Gonçalo

\section{Core Message}

> UV filters in sunscreens or cosmetics are the main cause of photoallergic contact dermatitis.

\subsubsection{Plants Causing Phytophotodermatitis} dermatitis" from perfumes is no more used [77]. in the sunny weather $[77,79,80]$ (Fig. 18.5).
Photoactive furocoumarins, e.g., bergapten, 5- and 8-methoxypsoralen, run in the sap of several plants, in variable amounts, as a protection against fungus and insects. Since the antiquity, these substances have been used in folk Medicine (vitiligo) and, more recently, in photochemotherapy (PUVA), and the aromatic oils rich in furocoumarins were used by the cosmetic industry in tanning oils and perfumes. As UV-induced skin pigmentation was proved to be a marker for DNA aggression, the use of tanning oils has been considerably reduced, and the natural bergamot oil responsible for "Berloque

Dermatitis can also occur from inadvertent contact with these plants, both during recreation or in an occupational setting, e.g., rural workers or gardeners who harvest fruits or vegetables (parsnip, figs) or cut bushes and weeds (common rue - Ruta graveolans - burning bush - Dictamus albus - or fig trees - Ficus carica) [77, 78], or barmen who squeeze and peal lime (Citrus aurantifolia) and other citrus fruits to prepare cocktails

The most typical pattern of phytophotodermatitis was described by Oppenheim in 1934 -dermatosis bullosa

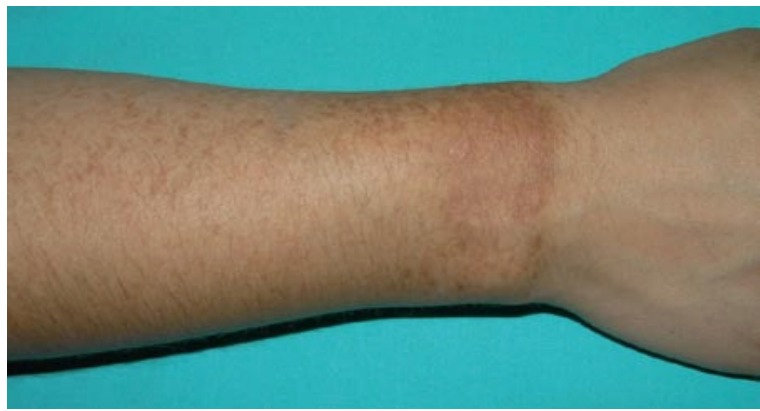

Fig. 18.5 Residual pigmentation in the forearms in a barman who had been squeezing limes and lemons for cocktails, during an outdoor summer festival (note limit due to glove protection) striata pratensis. Linear streaks, corresponding to the 541 contact with the damaged leaves of the plant, begin 542 within $24-48 \mathrm{~h}$ with prickling erythema and, later, pain- 543 ful vesicles and bullae (Fig. 18.6). All these gradually 544 give rise to long-lasting linear hyperpigmentation, which, sometimes, allows a retrospective diagnosis [80].

Another pattern is the "strimmer dermatitis" with a 547 diffuse involvement as the sap of the plant is sprayed 548 all over by the string trimmer [77]. Children who play 549 in nature were more prone to this dermatitis and, very 550 particularly, those making trumpets or pea shooters from the hollow stems of the giant hogweed (Heracleum mantegazzianum) developed blisters around their mouth [77]. Very occasionally, the ingestion of these plants can induce a systemic photosensitivity as in the cases of celery, parsnip, or infusions of St. John's wort (Hypericum perforatum L.) used to treat depression $[77,81]$.

Plants rich in furocoumarins causing phytophotodermatitis occur all over the globe and belong mainly to the families of Umbelliferae, Rutacea, and Moracea (Table 18.3).

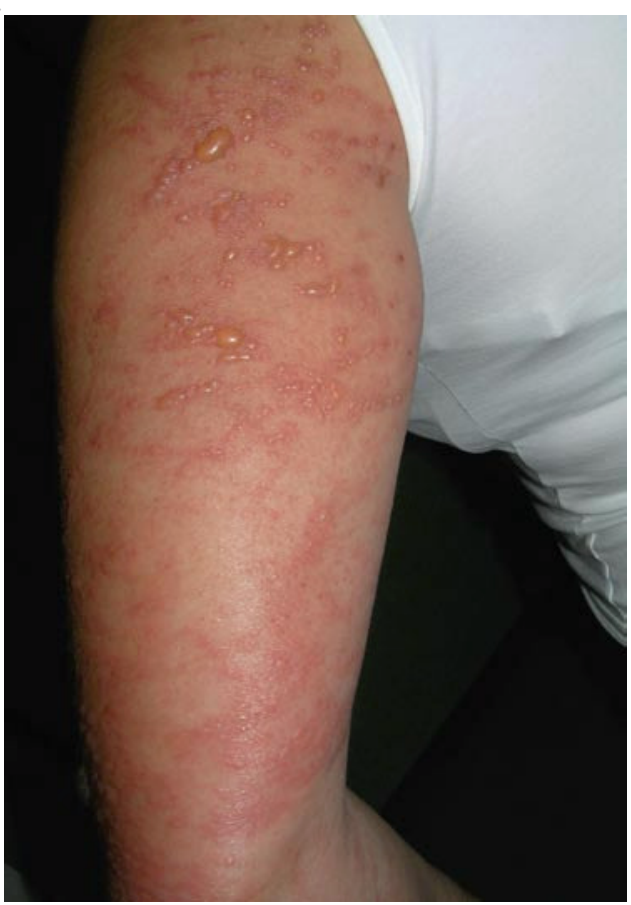

Fig. 18.6 Phytophotodermatitis with linear streaks of erythema and bullae in the arms of a patient who had been cutting a fig tree during a sunny afternoon 


\section{Author's Proof}

18 Phototoxic and Photoallergic Reactions

\section{Table 18.3 Main agents causing exogenous photosensitivity}

Sunscreens

Benzophenones: oxybenzone, sulisobenzone, mexenone

Dibenzoylmethanes: butyl methoxydibenzoylmethane

Cinnamates: isoamyl-p-methoxycinnamate, ethylhexyl methoxycinnamate

PABA and analogs: $p$-aminobenzoic acid; padimate $\mathrm{O}$

Other: 4-methylbenzylidene camphor, phenylbenzimidazole sulfonic acid, octocrylene, drometrizole trisiloxane

Plants (main Families in Europe)

Umbelliferae: Ammi majus, Apium graveolens (celery), Pastinaca sativa (parsnip), Petroselinum crispum (parsley), Heracleum mantegazzianum (giant hogweed)

Rutacea: Citrus spp, Citrus aurantica v. bergamia (bergamot), Citrus aurantifolia (lime), Citrus limon (lemon), Ruta graveolans (common rue), Dictamus albus (burning bush)

Moracea: Ficus carica (fig)

Drugs (see details in Table 18.4)

"Historical" photosensitizers ${ }^{\mathrm{a}}$

Perfumes: musk ambrette and bergamot oil

Halogenated salicylanilides: tetrachlorsalicylanilide, trichlorocarbanilide, tribromsalicylanide

Sunscreens: isopropyldibenzoylmethane, PABA

Antibiotics: olaquindox

Dyes: eosin, acridine orange, and acriflavin

aAlthough "historical," some still induce photoallergic contact dermatitis

\section{Core Message}

> Dermatosis bullosa striata pratensis, with linear lesions that regress with hyperpigmentation, is a phototoxic dermatitis from psoralen rich plants.

\subsubsection{Photosensitive Drugs}

According to the results of the photopatch series in Southern European countries, drugs are by far the main cause of exogenous photoallergy, whereas in the Northern countries sunscreens occupy the first rank as photosensitizers [62, 64-66]. This may be due to different prescription habits or because NSAIDs, the main drugs responsible for positive photopatch tests, were 570 not regularly included in most photopatch test series. 571

Drugs used systemically, applied topically, or han- 572 dled in an occupational setting can induce photosensi- 573 tivity. Carprofen, a NSAID no more used in humans, 574 induced photoallergic contact dermatitis in workers 575 who manufacture the drug for animals [82, 83]. Also, 576 we observed cases of photosensitivity in nurses and 577 family members who had to smash the tablets of chlor- 578 promazine to give to their patients/relatives [62]. 579

Systemically, antimicrobials, particularly tetracyclines, $\quad 580$ fluorquinolones, sulfonamides, and some antifungals 581 (voriconazole, griseofulvin), NSAIDs, phenothiazines, 582 and cardiovascular drugs are mainly responsible for photosensitivity, whereas after topical application, NSAIDs are by far the most frequent cause [62, 64-66].

\section{Core Message}

> Topical NSAIDs (ketoprofen) and systemic antibiotics (fluorquinolones, tetracyclines) can induce photoallergic contact dermatitis or systemic photosensitivity.

\subsubsection{Antimicrobials}

Systemic tetracyclines, particularly doxycycline and minocycline, are highly phototoxic and induce photoonycholysis and pseudoporphyria and, the latter can also induce a bluish persistent pigmentation [51, 52] (Fig. 18.4).

The fluorquinolones induce phototoxic reactions, in some cases presenting as pseudoporphyria [40], as initially described for the first quinolone antibiotic, nalidixic acid [51], or as purpura in a case by ciprofloxacin [53]. Phototoxicity is particularly important and frequent (4-15\% of treated patients) with fleroxacin, lomefloxacin, sparfloxacin, and pefloxacin and less frequent with ciprofloxacin, norfloxacin, ofloxacin, and enoxacin [14]. This can be reduced with drug intake by the end of the day, to reduce drug concentrations in the circulation and in the skin during the midday. Photoallergy has also been reported with lomefloxacin [20, 21] and enoxacin [51], sometimes with cross-reaction to other fluorquinolones (ciprofloxacin and flerofloxacin) [84, 85]. Experimental

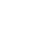
15

\section{.}

\section{0} .

\section{3}


studies proved the photoallergenicity of fluorquinolones, with positive lymphocyte stimulation tests and drug specific Th1 cells that recognize skin cells combined with UV-irradiated ofloxacin [86]. The fluorquinolones also photosensitize DNA and may be photomutagenic and photocarcinogenic [8]. We had the opportunity to observe a patient on long-term ciprofloxacin therapy for multiresistent tuberculosis, who developed photosensitivity and highly aggressive squamous cell carcinomas on the face.

Sulphonamide antibacterials, as well as sulfa-drug analogs (thiazidic diuretics, hypoglycemic sulfonylureas, and celecoxib) and dapsone (diamidiphenylsulfone), have been reported to cause photosensitivity within the spectrum both of UVB and UVA [51, 87, 88], but this side effect is not so frequent with the most currently used cotrimoxazole (trimethoprim/sulfamethoxazole) [14, 51].

Griseofulvin is a known phototoxic drug and can aggravate lupus erythematosus, as the more recent antifungal, terbinafine, which also induced subacute lupus erythematosus in patients with anti-Ro antibodies [55]. Another antifungal, still from a different chemical group, voriconazole, has recently been reported to cause severe photosensitivity [7] and was considered responsible for skin cancer [16, 28, 43].

\subsubsection{Nonsteroidal Anti-Inflammatory Drugs}

Benoxaprofen marketed between 1980 and 1982 called the attention to photosensitivity from this class of drugs. Thereafter, all the other arylpropionic derivatives (carprofen, naproxen, suprofen, tiaprofenic acid, ketoprofen, ibuprofen) and NSAIDs from other groups (azapropazone, diclofenac, piroxicam, fenilbutazone, celecoxib, benzydamine, etofenamate) have been shown to cause photosensitivity [39].

Most topically applied NSAIDs are absorbed through the skin and cause distant lesions, resembling systemic photosensitivity. Benzydamine, widely used in the oral or genital mucosa, causes photosensitivity at distant sites [89], eventually after systemic absorption $[29,65]$ and, when used in the mouth, can induce cheilitis and chin dermatitis as a manifestation of photoallergy [29, 62].

Although not the most sold, ketoprofen and piroxicam cause most cases of photosensitivity [62, 64, $65,90]$. Contrary to most other drugs, photoallergy is mainly involved with very particular patterns of cross- 653 reactivity.

Ketoprofen, particularly when used topically, is respon- 656 sible for severe photoallergic reactions [7, 91], often 657 with edema, bullae or erythema multiform, extending 658 well beyond the area of application [34, 35, 92], due to 659 contamination of the hands or other personal objects or 660 due to systemic absorption [92]. Reactions may recur 661 on sun exposure with no apparent further drug applica- 662 tion [34, 91], but they do not fulfill the criteria for the 663 diagnosis of persistent photosensitivity. Some may be 664 explained by persistence of the drug in the skin (at least 665 17 days) [92] by contact with previously contaminated 666 objects, even after washing [26], or from exposure to 667 cross-reactive chemicals [34].

Although such a high frequency might suggest phototoxicity, the clinical pattern with erythema multiform, positive lymphocyte stimulation tests with ketoprofen photomodified cells, animal studies with the absence of phototoxic potential [93], the capacity to photosensitize and transfer photoallergy by T-cells, both CD4 and CD8 exhibiting chemokine receptors for Th1 and Th2, in vitro activation and maturation of antigen-presenting cells by ketoprofen and UVA, [35, 94, 95], and characterization of a stable photoproduct - 3-ethyl-benzophenone $[34,96]$ - highly support a photoallergic reaction.

Cross-reactions occur between arylpropionic acid derivatives that share the benzophenone radical, namely tiaprofenic acid and suprofen, and are not extensive to naproxen or ibuprofen. As that radical is common to the benzophenone UV filters, cross-reactions are common with sunscreens containing mainly oxybenzone [96]. A similar structure is present in the systemic hypolipemic agent, fenofibrate, that also induces systemic photosensitivity with cross-reactions with ketoprofen [62] and, in patients taking this drug, it was a risk factor for more severe photoallergic contact dermatitis from ketoprofen $[91,96]$.

These patients have a higher reactivity, in patch tests, to balsam of Peru and perfume mix I, particularly cinnamic aldehyde [34, 97], still not completely explained.

Analogs of ketoprofen, piketoprofen, and dexketoprofen also cause photosensitivity with cross-reactivity to ketoprofen $[98,99]$. 


\section{Author's Proof}

18 Phototoxic and Photoallergic Reactions

\section{Piroxicam}

Piroxicam is a well-known photosensitizer since the 80s. Although there was some enigma to explain this photosensitivity at the beginning [100], soon a relation was established with contact sensitivity to thiomersal [101, 102], more precisely to thiosalicylic acid [24], one of the sensitization moieties most frequently responsible for contact allergy to thiomersal [103]. Actually, upon low UVA irradiation, piroxicam decomposes and gives rise to a photoproduct structurally similar to thiosalicylic acid, UVA-irradiated solutions of piroxicam induce positive patch tests in thiosalicylic allergic patients [24, 39, 103, 104], animals sensitized by thiosalicylic acid develop photosensitivity from piroxicam, and their lymphocytes are stimulated both by thiosalicylic acid and by piroxicam, in the presence of UVA [25].

Photoallergy from piroxicam can occur both from topical application and systemic use and, although it is becoming less frequent, probably because of the replacement of this NSAIDs by the newer drugs [23], it is still observed in Southern Europe [29, 64-66].

Systemic photosensitivity usually occurs within 24-48 $\mathrm{h}$ after the first drug intakes, as the individuals have been previously been sensitized though thiomersal. It can present as an acute eczema involving diffusely the whole face (Fig. 18.2) or, often, as scattered erythematosus papules and vesicles on the face and dorsum of the hands and dyshidrosis $[19,23,105,106]$

These patients do not react, neither on photopatch nor on drug rechallenge, to tenoxicam, meloxicam, or lornoxicam, as these oxicams do not share the thiosalicylate moiety [24, 107]. Nevertheless, it is important to remember that cross-reactivity between piroxicam and these oxicams occurs regularly in fixed drug eruption [108, 109].

\subsubsection{Other Drugs as Photosensitizers}

Phenothiazines used systemically (chlorpromazine and thioridazine) can induce photosensitivity, often with a lichenoid pattern and with residual pigmentation [52] (Fig. 18.3). Promethazine, still being used as a topical antipruritic, at least in Portugal, Greece, and Italy $[62,66,110]$, and its analog chlorproethazine, which is being marketed in France as Neuriplege $\AA$ cream for muscle pain (Genevrier, Antibes, France) are frequent causes of photoallergic contact dermatitis in these countries $[111,112]$.

The list of drugs causing photosensitivity is very large and always increasing; therefore, whenever a patient has a photosensitive eruption a systematic inquiry for drugs should be carefully conducted (Table 18.4). The complementary methods for its diagnosis, photopatch testing and photoprovocation, will be the object of Chap. 29.

Table 18.4 Main drugs causing exogenous photosensitivity

Antimicrobials

Tetracyclines (doxycycline, minocycline)

Sulphonamides (sulfamethoxazole)

Fluorquinolones (lomefloxacin ${ }^{\mathrm{a}}$, ciprofloxacin $^{\mathrm{a}}$ )

Voriconazole, griseofulvin

Efavirenz

Nonsteroidal anti-inflammatory drugs (NSAIDs)

Arylpropionic acids

Ketoprofen, ${ }^{\mathrm{b}}$ tiaprofenic acid, ${ }^{\mathrm{a}}$ suprofen, naproxen, ibuprofen, ibuproxam, carprofen

Piroxicam $^{c}$

Benzydamine, ${ }^{\mathrm{a}}$ etofenamate ${ }^{\mathrm{d}}$

Azapropazone, diclofenac, fenilbutazone, indometacine

\section{Phenothiazines}

Chlorpromazine, thioridazine

Promethazine $^{\mathrm{a}}$, chlorproethazine

\section{Antidepressants}

Clomipramine, imipramine, sertraline

Cardiovascular drugs

Amiodarone, quinidine

Furosemide and thiazide diuretics

Anticancer agents

Paclitaxel, 5-fluoruracil, dacarbazine, methotrexate

\section{Miscellaneous}

Flutamide, sulfonylureas

Fenofibrate, simvastatin

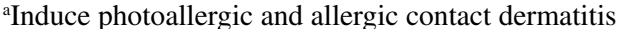

${ }^{\mathrm{b}}$ Although phototoxic, can induce photoallergic reactions

'Induces mainly systemic photoallergy

${ }^{\mathrm{d}}$ Induces mainly allergic contact dermatitis 


\subsection{Conclusions} and related chemicals.

\section{References} Press, Oxford 597-601 Photomed 20:175-183 Vénéreol 136:76-83
Phototoxic and photoallergic reactions are still a frequent problem, with a highly polymorphic clinical presentation and variations in the responsible agents according to geographical areas, and along the years, as new photosensitizers come into the market whereas others are abandoned. Therefore, we must be highly alert to suspect the involvement of an exogenous chromophore in a photosensitive patient, to conduct the questionnaire in this sense, and to proceed to further complementary tests to prove such a diagnosis and, consequently, advise the patient concerning further eviction of the photosensitizer

1. Hawk J (1999) Photodermatology, 1st edn. Oxford University

2. Fujimoto N, Danno K, Wakabayashi M et al (2009) Photosensitivity with eosinophilia due to ambroxol and UVB. Contact Derm 60:110-113

3. Darvay A, White I, Rycroft R et al (2001) Photoallergic contact dermatitis is uncommon. Br J Dermatol 145

4. Bryden A, Moseley H, Ibbotson S et al (2006) Photopatch testing of 1115 patients: results of the U.K. multicentre photopatch study group. Brit J Dermatol 155:737-747

5. Zeeli T, David M, Trattner A (2006) Photopatch tests: any news under the sun? Contact Derm 55:305-307

6. Bilu D, Mamelak A, Nguyen R et al (2004) Clinical and epidemiologic characterization of photosensitivity in HIV-positive individuals. Photoderm Photoimmunol

7. Béani J (2009) Les photosensibilisations graves. Ann Dermatol

8. Urbach F (1997) Phototoxicity and possible enhancement of photocarcinogenesis by fluorinated quinolone antibiotics. J Photochem Photobiol B 37:169-170

9. Klecak G, Urbach F, Urwyler H (1997) Fluoroquinolone antibacterials enhance UVA-induced skin tumors. J Photochem Photobiol B 37:174-181

10. Marrot L, Belaïdi J, Jones C et al (2003) Molecular responses to photogenotoxic stress induced by the antibiotic lomefloxacin in human skin cells: from DNA damage to apoptosis. J Invest Dermatol 121:596-606

11. Lhiaubet-Vallet V, Bosca F, Miranda M (2009) Photosensitized DNA damage: the case of fluoroquinolones. Photochem Photobiol 85:861-868

12. Müller L, Kasper P, Kersten B, Zhang J (1998) Photochemical genotoxicity and photochemical carcinogenesis - two sides of a coin? Toxicol Lett 102-103:383-387

13. Placzek M,Eberlein-König B, Przybilla B (1999) Association between actinic keratoses and potentially photosensitizing drugs. N Engl J Med 341:1474-1475
14. Ferguson J (1999) Drug and chemical photosensitivity. In: 805 Hawk's photodermatology, 1st edn. Oxford University Press, 806 Oxford, pp 155-169

15. Jensen A, Thomsen H, Engebjerg M et al (2008) Use of photosensitising diuretics and risk of skin cancer: a population based case-control study. Br J Cancer 99:1522-1528

16. McCarthy K, Playforf E, Looke D, Whitby M (2007) Severe photosensitivity causing multifocal squamous cell carcinomas secondary to prolonged voriconazole therapy. Clin Inf Dis 44:e55-e 56

17. Lim H, Hawk J (2008) Photodermatosis. In: Bolognia JL, Jorizzo JL, Rapini RP (eds) Dermatology, 2nd edn. Elsevier, Philadelphia

18. Karimian-Teherani D, Kinaciyan T, Tanew A (2008) 818 Photoallergic contact dermatitis from Heracleum giganteum. 819 Photoderm Photoimmunol Photomed 24:99-101 820

19. Gonçalo M (1998) Explorations dans les photo-allergies médi- 821 camenteuses. In: GERDA (eds) Progrès en Dermato- 822 Allergologie. John Libbey Eurotext. Nancy, France, pp 67-74 823

20. Oliveira H, Gonçalo M, Figueiredo A (1996) Photosensitivity 824 from lomefloxacin. A clinical and photobiological study. 825 Photoderm Photoimmunol Photomed 16:116-120 826

21. Kurumajin Y, Shono M (1992) Scarified photopatch testing 827 in lomefloxacin photosensitivity. Contact Derm 26:5-10 828

22. Neves B, Cruz M, Francisco V et al (2008) Differential mod- 829 ulation of CXCR4 and CD40 protein levels by skin sensitiz- 830 ers and irritants in the FSCD cell line. Toxicol Lett 177: 831 74-82

23. Serra D, Gonçalo M, Figueiredo A (2008) Two decades of 833 cutaneous adverse drug reactions from piroxicam. Contact 834 Derm 58:S35

24. Gonçalo M, Figueiredo A, Tavares P et al (1992) Photosensitivity to piroxicam: absence of cross-reaction with tenoxicam. Contact Derm. 27:287-290

25. Hariva T, Kitamura K, Osawa J, Ikezawa Z (1993) A crossreaction between piroxicam-photosensitivity and thiosalicylate hypersensitivity in lymphocyte proliferation test. J Dermatol Sci 5:165-174

26. Hindsén M, Isaksson M, Persson L et al (2004) Photoallergic contact dermatitis from ketoprofen induced by drug-contaminated personal objects. J Am Acad Dermatol 50:215-219

27. Due E, Wulf H (2006) Cheilitis - the only presentation of photosensitivity. JEADV 20:766-767

28. Auffret N, Janssen F, Chevalier P et al (2006) Photosensibilisation au voriconazole. Ann Dermatol Vénéreol 133:330-332

29. Canelas M, Cravo M, Cardoso J et al (2008) Dermatite de contacto fotoalérgica à benzidamina - Estudo de 8 casos. Trab Soc Port Dermatol Venereol 66:35-40

30. Kerr A, Ferguson J, Ibbotson S (2007) Acute phototoxicity with urticarial features during topical 5-aminolaevulinic acid photodynamic therapy. Clin Exp Dermatol 32:201-202

31. Collins P, Ferguson J (1994) Photoallergic contact dermatitis to oxybenzone. Br J Dermatol 131:124-129

32. Spijker G, Schuttelaar M, Barkema L et al (2008) Anaphylaxis caused by topical application of a sunscreen containing benzophenone-3. Contact Derm 59:248-249

33. Lovell C, Cronin E, Rhodes E (1986) Photocontact urticaria 863 from chlorpromazine. Contact Derm 14:290-291 864

34. Devleeschouwer V, Roelandts R, Garmyn M, Goossens A 865 (2008) Allergic and photoallergic contact dermatitis from 866 
ketoprofen: results of (photo) patch testing and follow-up of 42 patients. Contact Derm 58:159-166

35. Izu K, Hino R, Isoda $\mathrm{H}$ et al (2008) Photocontact dermatitis to ketoprofen presenting with erythema multiforme. Eur J Dermatol 18:710-713

36. Cohen P (2009) Photodistributed erythema multiforme: paclitaxel-related, photosensitive conditions in patients with cancer. J Drugs Dermatol 8:61-64

37. Mansur A, Aydingöz J (2005) A case of toxic epidermal necrolysis with lesions mostly on sun-exposed skin. Photoderm Photoimmunol Photomed 21:100-102

38. Redondo V, Vicente J, España A et al (1996) Photo-induced toxic epidermal necrolysis caused by clobazam. Br J Dermatol 135:999-1002

39. Figueiredo A (1994) Fotossensibilidade aos anti-inflamatórios não esteróides. Estudo fisiopatológico. Doctoral Thesis, Coimbra

40. Schmutz J, Barbaud A, Tréchot P (2008) Ciprofloxacin and pseudoporphyria. Ann Dermatol Vénéreol 135(11):804

41. Cummins R, Wagner-Weiner L, Paller A (2000) Pseudoporphyria induced by celecoxib in a patient with juvenile rheumatoid arthritis. J Rheumatol 27:2938-2940

42. Schmutz J, Barbaud A, Tréchot P (2006) Pseudoporphyria and coxib. Ann Dermatol Vénéreol 133:213

43. Tolland J, McKeown P, Corbett J (2007) Voriconazole-induced pseudoporphyria. Photoderm Photoimmunol Photomed 23: 29-31

44. Timmer-de Mik L, Kardaun S, Krammer M et al (2009) Imatinib-induced pseudoporphyria. Clin Exp Dermatol 34(6):705-707

45. Passier A, Smits-van Herwaarden A, van Puijenbroek E (2004) Photo-onycholysis associated with the use of doxycycline. BMJ 329:265

46. Baran R, Juhlin L (2002) Photoonycholysis. Photoderm Photoimmunol Photomed 18:202-207

47. Gregoriou S, Karagiorga T, Stratigos A et al (2008) Photoonycholysis caused by olanzapine and aripiprazole. J Clin Psychopharmacol 28:219-220

48. Gonçalo M, Domingues J, Correia O, Figueiredo A (1999) Fotossensibilidad a Flutamida. Boletim Informativo del GEIDC 29:45-48

49. Vilaplana J, Romaguera C, Azón A, Lecha M (1990) Flutamide photosensitivity-residual vitiliginous lesions. Contact Derm 38:68-70

50. Ammoury A, Michaud S, PaulC et al (2008) Photodistribution of blue-gray hyperpigmentation after amiodarone treatment. Molecular characterization of amiodarone in the skin. Arch Dermatol 144:92-96

51. Vassileva S, Matev G, Parish L (1998) Antimicrobial photosensitive reactions. Arch Intern Med 158:1993-2000

52. Ferguson J (2002) Photosensitivity due to drugs. Photoderm Photoimmunol Photomed 18:262-269

53. Urbina F, Barrios M, Sudy E (2006) Photolocalized purpura during ciprofloxacin therapy. Photoderm Photoimmunol Photomed 22:111-112

54. Sontheimer R, Henderson C, Grau R (2008) Drug-induced subacute cutaneous lupus erythematosus: a paradigm for bedside-to-bench patient-oriented translational clinical investigation. Arch Dermatol Res 301:65-70

55. Farhi D, Viguier M, Cosnes A et al (2006) Terbinafine-induced subacute cutaneous lupus erythematosus. Dermatology 212: 59-65
56. Chen M, Crowson A, Woofter M et al (2004) Docetaxel 929 (taxotere) induced subacute cutaneous lupus erythematosus: 930 report of 4 cases. J Rheumatol 31:818-820

57. Hawk J (2004) Chronic actinic dermatitis. Photoderm Photoimmunol Photomed 20:312-314

58. Emmert B, Schauder S, Palm H et al (2007) Disabling work- 934 related persistent photosensitivity following photoallergic 935 contact dermatitis from chlorpromazine and olaquindox in a 936 pig breeder. Ann Agric Environ Med 14:329

59. Waters A, Sandhu D, Lowe G, Ferguson J (2009) Photocontact allergy to PABA: the need for continuous vigilance. Contact Derm 60:172-173

60. Schauder S, Ippen H (1997) Contact and photocontact sensitivity to sunscreens. Review of a 15-year experience and of the literature. Contact Derm 37:221-232

61. Sheuer E, Warshaw E (2006) Sunscreen allergy: a review of epidemiology, clinical characteristics, and responsible allergens. Dermatitis 17:3-11

62. Cardoso J, Canelas M, Gonçalo M, Figueiredo A (2009) Photopatch testing with an extended series of photoallergens. A 5-year study. Contact Derm 60:314-319

63. Bakkum R, Heule F (2002) Results of photopatch testing in Rotterdam during a 10 -year period. Br J Dermatol 146: 275-279

64. Leonard F, Adamski H, Bonnevalle A et al (2005) Étude prospective multicentrique 1991-2001 de la batterie standard des photopatch-tests de la Société Française de Photodermatologie. Ann Dermatol Vénéreol 132:313-320

65. La Cuadra-Oyanguren J, Pérez-Ferriols A, Lecha-Carralero M et al (2007) Results and assessment of photopatch testing in Spain: towards a new standard set of photoallergens. Actas Dermosifiliogr 98:96-101

66. Pigatto P, Guzzi G, Schena D et al (2008) Photopatch tests: an Italian multicentre study from 2004 to 2006. Contact Derm 59:103-108

67. Berne B, Ros A (1998) 7 years experience of photopatch testing with sunscreen allergens in Sweden. Contact Derm 38:61-64

68. Lowe N (2006) An overview of ultraviolet radiation, sunscreens and photo-induced dermatosis. Dermatol Clin 24:9-17

69. Andersen K, Goossens A (2006) Decyl glucoside contact allergy from a sunscreen product. Contact Derm 54:349-350

70. Andrade P, Gonçalo M, Figueiredo A (2009) Allergic contact dermatitis to decyl glucoside in Tinosorb M. Contact Derm 62:119-120

71. Gonçalo M, Ruas E, Figueiredo A, Gonçalo S (1995) Contact and photocontact sensitivity to sunscreens. Contact Derm 33:278-280

72. Hughes T, Stone N (2007) Benzophenone 4: an emerging allergen in cosmetics and toiletries? Contact Derm 56:153-156

73. Torres V, Correia T (1991) Contact and photocontact allergy to oxybenzone and mexenone. Contact Derm 25:126-127

74. Kunz P, Fent K (2006) Estrogenic activity of UV filter mixtures. Toxicol Appl Pharmacol 15:86-99

75. Singh M, Beck M (2007) Octyl salicylate: a new contact sensitivity. Contact Derm 56(1):48

76. Madan V, Beck M (2005) Contact allergy to octocrylene in sunscreen with recurrence from passive transfer of a cosmetic. Contact Derm 53:241-242

77. Lovell C (2000) Phytophotodermatitis. In: Avalos J, Maibach HI (eds) Dermatological botany. CRC Press, Boca Raton, pp 51-65 
78. Gonçalo S, Correia C, Couto J, Gonçalo M (1989) Contact and photocontact dermatitis from Ruta chalepensis. Contact Derm 21:200-201

79. Wagner A, Wu J, Hansen R et al (2002) Bullous phytophotodermatitis associated with high natural concentrations of furanocoumarins in limes. Am J Contact Derm 13:10-14

80. Gonçalo M (2004) Dermatitis por plantas y maderas. Em: Conde-Salazar Gómez L, Ancona-Alayón A (eds) Dermatologia professional. Aula Médica Ediciones, Madrid, pp 193-210

81. Schempp C, Müller K, Winghofer B et al (2002) St. John's wort (Hypericum perforatum L.). A plant with relevance for dermatology. Hautarzt 53:316-321

82. Kerr A, Muller F, Ferguson J, Dawe R (2008) Occupational carprofen photoallergic contact dermatitis. Br J Dermatol 159:1303-1308

83. Walker S, Ead R, Beck M (2006) Occupational photoallergic contact dermatitis in a pharmaceutical worker manufacturing carprofen, a canine nonsteroidal anti-inflammatory drug. Br J Dermatol 154:551-577

84. Kimura M, Kawada A (1998) Photosensitivity induced by lomefoxacin with cross-photosensitivity to ciprofloxacin and fleroxacin. Contact Derm 38:130

85. Correia O, Delgado L, Barros M (1994) Bullous photodermatosis after lomefloxacin. Arch Dermatol 130:808-809

86. Tokura Y, Seo N, Fujie M, Takigawa M (2001) Quinolonephotoconjugated major histocompatibility complex class II-binding peptides with lysine are antigenic for $\mathrm{T}$ cells mediating murine quinolone photoallergy. J Invest Dermatol 117:1206-1211

87. Kar B (2008) Dapsone-induced photosensitivity: a rare clinical presentation. Photoderm Photoimmunol Photomed 24: 270-271

88. Yazici A, Baz K, Ikizoglu G et al (2004) Celecoxib-induced photoallergic drug eruption. Int J Dermatol 43:459-461

89. Lasa Elgezua O, Gorrotxategi P, Gardeazabal Gracia J et al (2004) Photoallergic hand eczema due to benzydamine. Eur J Dermatol 14:69-70

90. Diaz R, Gardeazabal J, Manrique P et al (2006) Greater allergenicity of topical ketoprofen in contact dermatitis confirmed by use. Contact Derm 54:239-243

91. Veyrac G, Paulin M, Milpied B et al (2002) Bilan de l'enquête nationale sur les effets indésirables cutanés do kétoprofène gel enregistrés entre le 01/09/1996 et le 31/08/2000. Thérapie 57:55-64

92. Sugiura M, Hayakawa R, Kato Y et al (2000) 4 cases of photocontact dermatitis due to ketoprofen. Contact Derm 43: 16-19

93. Lee B, Choi Y, Son W et al (2007) Ketoprofen: experimental overview of dermal toxicity. Arch Toxicol 81:743-748

94. Imai S, Atarashi K, Ikesue K et al (2005) Establishment of murine model of allergic photocontact deermatitis to ketoprofen and characterization of pathogenic T cells. J Dermatol Sci 41:127-136

95. Hino R, Orimo H, Kabashima K (2008) Evaluation of the photoallergic potential of chemicals using THP-1 cells. J Dermatol Sci 52:140-143
96. LeCozC, Bottlaender A, Scrivener Jetal (1998) Photocontact dermatitis from ketoprofen and tiaprofenic acid: crossreactivity study in 12 consecutive patients. Contact Derm 38:245-252

97. Pigatto P, Bigardi A, Legori A et al (1996) Cross reactions in patch testing and photopatch testing with ketoprofen, tiaprofenic acid and cinnamic aldehyde. Am J Contact Derm 7:220-223

98. Asensio T, Sanchis M, Sánchez P et al (2008) Photocontact dermatitis because of oral dexketoprofen. Contact Derm 58:59-60

99. Fernández-Jorge B, Buján J, Paradela S, Mazaira M, Fonseca E (2008) Consort contact dermatitis from piketoprofen. Contact Derm 58:113-115

100. Lunggren B (1989) The piroxicam enigma. Photodermatology 6:151-154

101. Cirne de Castro J, Vale E, Martins M (1989) Mechanism of photosensitive reactions induced by piroxicam. J Am Acad Dermatol 20:706-707

102. Cirne de Castro J, Freitas J, Brandão F, Themido R (1991) Sensitivity to thimerosal and photosensitivity to piroxicam. Contact Derm 24:187-192

103. Gonçalo M,Figueiredo A, GonçaloS (1996)Hypersensitivity to thimerosal: the sensitizing moiety. Contact Derm 34: 201-203

104. Ikezawa Z, Kitamura K, Osawa J, Hariva T (1992) Photosensitivity to piroxicam is induced by sensitization to thimerosal and thiosalicylate. J Invest Dermatol 98:918-920

105. Varela P, Amorim I, Massa A, Sanches M, Silva E (1998) Piroxicam-beta-cyclodextrin and photosensitivity reactions. Contact Derm 38:229

106. Youn J, Lee H, Yeo U, Lee Y (1993) Piroxicam photosensitivity associated with vesicular hand dermatitis. Clin Exp Dermatol 18:52-54

107. Trujillo M, Barrio M, Rodríguez A et al (2001) Piroxicaminduced photodermatitis. Cross-reactivity among oxicams. A case report. Allergol et Immunopathol 29:133-136

108. Gonçalo M, Oliveira H, Fernandes B etal (2002) Topical provocation in fixed drug eruption from nonsteroidal antiinflammatory drugs. Exog Dermatol 1:81-86

109. Oliveira H, Gonçalo M, Reis J, Figueiredo A (1999) Fixed drug eruption to piroxicam. Positive patch tests with crosssensitivity to tenoxicam. J Dermatol Treat 10:209-212

110. Katsarou A, Makris M, Zarafonitis G et al (2008) Photoallergic contact dermatitis: the 15 -year experience of a tertiary reference center in a sunny Mediterranean city. Int J Immunopathol Pharmacol 21:725-727

111. Barbaud A, Collet E, Martin S et al (2001) Contact sensitization to chlorproéthazine can induce persistent light reaction and cross photoreactions to other phenothiazines. Contact Derm 44:373

112. Kerr A, Woods J, Ferguson J (2008) Photocontact allergic and phototoxic studies of chlorproethazine. Photoderm Photoimmunol Photomed 24:11-15
1048 


\section{Author's Proof}

\section{Author Queries}

Chapter No.: 18

\begin{tabular}{|l|l|l|}
\hline Query & Details Required & Author's Response \\
\hline AU1 & $\begin{array}{l}\text { Technical terms have been spelled wrongly in many instances. We have corrected them. Please } \\
\text { check the same. }\end{array}$ & \\
\hline AU2 & Please check whether the edited table18.2 is appropriate. & \\
\hline AU3 & Please check whether the edit is ok. & \\
\hline AU4 & $\begin{array}{l}\text { In the sentence, 'Systemically, antimicrobials...' please check if the insertion of the words 'for } \\
\text { photosensitivity' is appropriate. }\end{array}$ & \\
\hline AU5 & Please confirm this deletion. & \\
\hline AU6 & Please mention the appropriate year. & \\
\hline
\end{tabular}

